\title{
Neural network management of technological systems at the finish operations
}

\author{
Irina Ovsyanikova ${ }^{1, *}$ and Aleksandr Tarapanov ${ }^{1}$ \\ ${ }^{1}$ Orel State University of I.S. Turgenev, Orel, Rassian Federation
}

\begin{abstract}
In the article, problems of forming systems management on final operations by means of the neural networks providing high quality of functioning in conditions of uncertainty (insufficiency) of information about the control object and the external environment are considered. It is emphasized that neural networks define the most informative set of the diagnosing attributes and establish a strict correlation between a process condition and results of indirect measurements. It is also shown that the networks containing nonlinear components can be used for approximation of nonlinear mapping with any desirable degree of accuracy; parameters of neural networks can be adjusted in real time considering the input/output data. Advantages of back-propagation neural networks at management of process systems of final operations in order to ensure high quality of providing products are given.
\end{abstract}

\section{Introduction}

In modern mechanical engineering, the considerable part of output product is the multiproduct and small-lot manufacture. High requirements are made to the final transactions influencing the quality of the products. It predetermines ensuring of high reliability and fast adaptation of machines to constantly changing modes of functioning and the nomenclature of the details.

The solution to the common problem, and its practical embodiment in the integrated automated (integrated programmed) production is possible only when all separate tasks are implemented.

Regardless of the presence or the absence of information preprocessing (selection of the main attributes, conversion to different form in the new parametric space, etc.), the signal of transformation of process system will represent the vector in any parametric space. Then this vector is compared to the vectors used at the training stage. The majority of neural network models uses described transaction.

\section{Problem description}

Input and current information about the state of process system and perturbations of the environment becomes the main factor for neural network (NN) management in order to develop the algorithm of training/management.

By manipulating the range of the input signal, eventually, it is possible to receive NN with optimum properties and parameters.

Despite the numerous works devoted to the theoretical modeling and pilot studies of machines, state of the technology equipment with alternative system positions cannot be completely predicted. Therefore, the quality of processed details can only be stated. Virtually all the serial equipment is provided only with local communications that causes low "controllability" and "observability" by output criteria. The main feedback on output parameters is implemented in rare cases [1].

Indirect assessment of technological process is extremely important as it is almost only one information base of the automated equipment adjusting in the course its operation when the impacts and parameters are constantly changing.

The reference to the system managed by an artificial intelligence is connected with "illegibility" of the considered objects. At the same time, the illegibility of images, representations and conceptions is introduced into formal models by different methods.

Selection from the signal of images familiar to the system and its subsequent representation by neurons is performed on the input-output level. Input vectors are fuzzy through both training and recognition, i.e. there is the small dispersion of the vectors belonging to one class. In this context, the neuronet performing this operation shall have the certain capability to statistical averaging $[2$, $3,4]$.

\section{Formal model of electroerosive manufacture}

The generalizing capability of back-propagation network allows to obtain the correct output at management of process systems of metalworking even with incomplete or partly incorrect input vector. Also the network has the remarkable property to successfully process the noisy, distorted or partially damaged information [5 - 7].

Final operations of technological process almost completely determine the accuracy and quality of the surface of the produced products. In the single-piece and small-lot production, electron discharge machining

\footnotetext{
*Corresponding author: ovsynikova2012@yandex.ru
} 
(EDM) is widely used as a final transaction at the production of such high-precision products as compression moulds and stamps, which are in turn define the quality of the details.

The key objective of increasing the efficiency and quality of electron discharge machining (EDM) is to find the optimum modes of the accompanying processes, determine the linkages between the input and output processing parameters in order to reduce the wear of the tool - electrode (ET).

Because of the small duration and high power of single discharge, the metal layer on the processed section melts, the major part of power is the share of destruction of the surface layer. Change of energy of single discharge is defined by the form of the impulse and current-voltage characteristic of the pulse generator.

Technological indicators of processing, namely, the roughness $\mathrm{Rz}$, microns, productivity $\mathrm{M}, \mathrm{mm} 3 / \mathrm{min}$., depend on the working pulse-repetition rate $\mathrm{f}, \mathrm{kHz}$, porosity q, current intensity I, A, voltage U, V. Height of microroughnesses of $\mathrm{Rz}$, microns, shall not exceed 20 microns with the maximum performance considering thermal-physical properties of materials ET and the processed detail.

The temperature of the working environment in the processing zone influences the physical state of the interelectrode distance (ID). These thermal processes are connected with the performance of EDM, the quality of the processed surface and wear of ET. When the temperature of working environment increases, its heat capacity and viscosity, as well as its cooling capability and the possibility of capture and carrying out of the products of the erosion from ID decreases.

All above-mentioned factors indicate the possibility of management or improvement of performance and quality of the surfaces, processed by the electron discharge machining method due to increasing the zone of power costs on electrodischarge destruction by the method of the parameters of impulses optimization.

The management systems based on different methods of management which can be divided into three main groups are applied to obtain necessary parameters of process of EDM:

- feed control EI is carried out by means of the closed simple autonomous circuit of management;

- program control - provides installation of parameters of the processing or the choice of empirical or theoretical parameters of processing;

- adaptive control - carries out a continuous complex process evaluation of processing and installation of parameters during the process of EDM.

The different combinations of the described systems are used. The role of adaptive management system consists in the identification and elimination of all deviations of process from its normal course $[8,9]$.

One of the important indicators of EDM-process of EEO is process stability. Stability is considered as a capability to keep during the certain period of time the continuous process of metal removal and evacuation of products of the erosion, despite the emergence of the accidental or natural disturbance influences in the system.

For determination the desired combinations of the parameters providing the most productive mode, it is necessary to know the optimum value of the duration or porosity of the impulse with different pulse-repetition rate for certain data of working areas and currents. Thus, for each mode it is necessary to determine the optimum value of porosity [8].

The sequence of choosing the mode of electron discharge machining for copy-piercing machine is as follows:

- determination of model of the machine and pulse generator, determination of material and parameters of ET-quality, type of dielectric liquid and its filtration degree, polarity of electrodes connection;

- the form of digit pulse is adjusting by taking into account the material of the detail and the wearing depth of $\mathrm{ET}$, the form and the required roughness of the processed surface;

- parameters of impulses are set;

- admission controller for receiving working impulses with the certain pulse-repetition rate frequency is configured;

- rate and injection pressure of working liquid are set; frequency of relaxation and vibration of electrodes is determined depending on the value of working current and the wearing depth of ET;

- electrode gaps are checked and changes are made to the tool sizes, processing time is defined.

System synergistic approach [7] is the most promising direction in the complex studying of electric discharge processes and the mechanism of formation of the surface layer of blank. According to the approach, process of electron discharge machining should be considered as a system of dissipative processes. The majority of technological processes of EDM cannot be presented in the form of simple systems, therefore, the approach based on the synthesis the component is applied for formalization of processes of the processing zone.

The main principle of synthetic information modeling is the "black box" principle, when external functioning of the system is modelled merely informational. Set of the dissipative processes occurring in the processing zone should be consider as the "black box"; estimated values of the dependent parameters of EDM, such as tool wear rate, slag, temperature in the processing zone, etc., are the output data.

Information modeling is applied to create the management model allowing to create the process environment and to virtually manage it, avoiding the influence of the arbitrary factors present at the practical experiment. Special "miscalibration" parameters are introduced into the model in order to calculate the probabilistic assessments. The main objective of information modeling is to ensure required output values of the EDM parameters; and the indirect problem is to minimize the influence of arbitrary factors.

In the literature [2-9] the proofs that there is the neural network $(\mathrm{NN})$ for any algorithm are given. $\mathrm{NN}$ allows to model nonlinear processes, to work with noisy data and to adapt to any external influences.

The model of the management system is based on the fully connected neural networks, since the NN have the 
biggest number of connectivity under the same number of neurons; that in turn increases the data capacity of the network. Fully connected network configuration is the most universal and does not require experiments with connection diagrams for each task. In case of network emulation on the average computer, fully connected network has significant features in the functioning speed, simplicity of implementation without affecting the quality of trainability.

A possibility of application of neural networks for solving the management problem is based on the fact that $\mathrm{NN}$ consisted of two layers and having a random large number of nodes in hidden layer can approximate any function of real numbers with the desired accuracy. Therefore NN with one hidden layer can be used to solve management tasks.

Adaptive control NN are designed so that the output signal of the managed model corresponds to the output signal of previously defined model, which has required characteristics. Structurally NN has at least two inputs, and one or several outputs. The output signal represents the weighted sum of input signals, and this amount depends on the values and relations between input signals. The following parameters are supplied into the system: porosity q, current intensity I, voltage $\mathrm{U}$ (which define the impulse form); consumption and power liquid circulation pressure; frequency of the relaxation and vibration of electrodes; interelectrode gaps and sizes of the tool; processing time. Output parameters are unloading V of metal and the received height $\mathrm{Rz}$ of microroughnesses.

The system should be asymptotically stable, the managed system tracks the reference model with the zero error; transition processes at the stage of adaptive control or the training management have the guaranteed limits.

Management based on the training principle means the gradual accumulation of experience of system behavior at a high degree of uncertainty of its initial states. Improvement of system functioning occurs by the results of system behavior. Nature of experience accumulation during the learning is manifold, for example, accumulated experience can be positive or negative, systematized or accidental, own or introduced, simulation (artificial) or natural, etc. However, all accumulation methods have a common feature, which is gradual separation of knowledge domain from all set of ignorance. Therefore, in the theory of the taught systems this feature is reflected in rather quickly developing direction connected with the development of automatic systems of classification or image identification.

Objective complexity of training, both with and without encouragement, is that the classes from the nearest points of the managed space are separable. In other words, intersections of classes when the same points belong to different classes are possible.

The main objective is to determine the most informative set of the diagnostic attributes and to establish the correlation between the state of forming process and results of indirect measurements.

The majority of the known models is based on the regression or correlation dependences obtained by statistical processing of experimental data.
At any recognition algorithm, there has always been the procedure of comparison of the input signal with the standards, which are available in memory.

It is necessary to clarify the parameters of network after defining its general structure. The parameters of the network are the amount of input and output neurons, the number of neurons of Kokhonen and Grossberg layers, and values of synaptic connections.

Back-propagation network (BP) works with the continuous or binary vectors consisting of zero and units. As a result of learning, input vectors are associated with the output data. When the network is trained, supplying the input images results in the output data. The correct output can be obtained when the input is incomplete or a partially incorrect. The hypersurface received as a result of the functioning of BP network, provides the possibility of forecasting because of the continuity principle. It is clear that the forecasting will be more precise inside the hyperparallelepiped of training images; an error will be greater at the solution of the extrapolation problem.

The BP network consists of two layers of neurons (fig. 1): Kokhonen's layer and Grossberg's layer. Neurons of Kokhonen's layer work by the principle "the winner takes it all" in the mode of functioning (recognition), defining the cluster to which the input image belongs. Then the output star of the Grossberg's layer reproduces the corresponding image on the outputs of the network by a signal of the winner neuron in Kokhonen's layer.

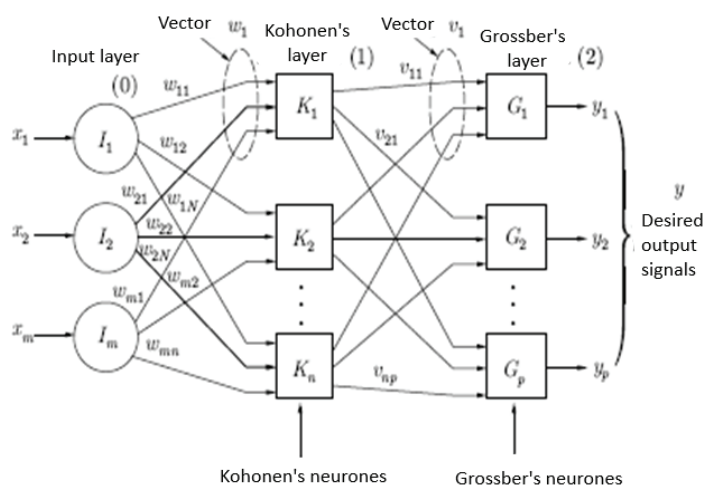

Fig. 1. Back-propagation network

Like other networks, the BP-network works in two modes: training and working. In the first case, weighted coefficients are adjusted with the vectors $\mathrm{X}$ and $\mathrm{Y}$ as input; in the second mode $\mathrm{Y}$ or $\mathrm{X}$ are the input of already trained network, and both $\mathrm{X}$ and $\mathrm{Y}$ are the output. In comparison with the different networks, back-propagation network is trained much quicker, but the accuracy of result is less.

Researches of the last years [5 - 11] showed that the parallel configuration of neuronets provides increased speed of calculations. The networks containing nonlinear components can be used for approximation of nonlinear images with any desirable accuracy degree.

Training by the algorithm of error back-propagation assumes direct and the return passes over all layers of network. At the forward pass the input vector is supplied on the input layer of neural network, then it extends from 
one layer to another. This resulted in generating of the set of output signals, which is the practical reaction of network to this input image.

During the forward pass all synaptic weights of network are fixed. During the backward pass all synaptic weights are adjusted according to the rule of error correction, namely: the actual output of network is subtracted from the desirable, therefore the signal of error is generated. Subsequently, this signal distributes in the direction, which is opposite to the direction of synaptic connections. Synaptic weights are adjusted to ensure the maximum approach of the output signal of network to the desirable $[4,11]$.

Presence of the layer of the matrix of coefficients allows the neuronet to weigh input signals, using the set of signal transmission routes by summing up them on with the its own weights. As a result, each combination of all input signals changing in some set ranges will correspond to the value of the output signal.

Nowadays, the number of different architecture of neural network management systems construction are well developed and widely used. Generation of adequate control signal for management of dynamics of the control object states is performed by neural net controller.

State transition is performed by the optimum trajectory; algorithm of error back-propagation, which is one of methods of training of the multilayer neural networks of direct distribution, also called multilayer perceptron, is used as the training algorithm. This iterative gradient algorithm is used in order to minimize the error of the multilayer perceptron work and to receive the acceptable output [8].

To date, large market of neural network products is formed. The modern level of development of microelectronics allows to produce the neurochips consisting of very large number of the simple elements capable to perform only arithmetic transactions. The vast majority of products is presented in the form of the modeling software. The leading companies develop specialized neurochips or neuroboards in the form of addon devices to usual computers $[4,5,9,10]$.

The hardware neurosystems are rather expensive and primarily intended for professional use.

It is possible to use NeuroShell 2.0 for the research purposes. The advantage of this program is compatibility with the popular packet of data management Microsoft Excel that makes the product convenient for mass use. The nAPL programming language, problem-oriented for the neuronet, programming environment in $\mathrm{C}++$ and the UNIX-compatible operating system allow to develop neural network systems of EDM management.

The main increment of productivity is provided due to application of parallel analog multiplication of input signals by weight coefficients.

The combination of concepts, methods and mathematic of the modern nonlinear management theory with the theory of the learning artificial neural networks gives great opportunities for structural synthesis of complex dynamic management systems of EDM, allowing to receive the effective combination of performance and parameters of quality of the processed surface.

\section{Conclusions}

1. Including the neural networks in the management system will allow to distinguish essentially new properties: the system will obtain the capability to understand and study the processes and operating conditions, accumulating the gained knowledge and to intentionally use it for improvement of quality characteristics.

2. The integration of modern information technologies into technological process allow to increase processing accuracy. New management systems including all complex of modern equipment guarantee repetition of the programmed geometry with the high precision rate.

3. Neural networks are designed so that the output signal of the managed technological system corresponds to the output signal of previously defined model, which has required quality characteristics.

4. In comparison with the different networks, backpropagation network is trained much quicker, but the accuracy of result is less. The capability of network allows to obtain the correct output at management of process systems of metalworking even with incomplete or partly incorrect input vector. In addition, the network has remarkable property to successfully process the noisy, distorted or partially damaged information.

\section{References}

1. B.M. Brzhozovskij, M.B. Brovkova, V.V.Martynov Opredelenie parametrov kachestva izdelij pri mehanoobrabotke v real'nom vremeni na osnove nejrosetevyh algoritmov // Nelinejnaja di $\neg$ namika i prikladnaja sinergetika: Materialy Mezhdunar. konf. - Komsomol'sk-na-Amure, pp.62-65. (2003)

2. L.N. Jasnickij Vvedenie v iskusstvennyj intellekt : ucheb. posobie dlja stud. vyssh. ucheb. zavedenij $L$. N. Jasnickij. -- 2-e izd., ispr. -- M. : Izdatel'skij centr «Akademija», p.176 (2008)

3. T.Kohonen Self-organization and associative memory. Series in Information Sciences, vol. 8. Berlin: Springer Verlag p.82 (1984)

4. Hajkin Sajmon. Nejronnye seti. Polnyj kurs 2-e izd., ispr.: Per. s angl. - M.: OOO «I. D. Vil'jams», p.1104 (2006)

5. R. Dorf, R. Bishop Sovremennye sistemy upravlenija /Per. s angl. B. I. Kopylova. - M.: Laboratorija bazovyh znanij, p.832 (2009)

6. A.Galushkin Nejronnye seti. Osnovy teorii - M.: Gorjachaja Linija - Telekom, p.496 (2012)

7. I.V. Ovsyanikova, Upravlenie parametrami processa formirovanija slozhnyh poverhnostej./I.V. Ovsyanikova, A.S. Tarapanov, V.S. Shorkin «Fundamental'nye i prikladnye problemy tehniki i tehnologii» №2 , Gosuniversitet - UNPK, Orel, p.56-60 (2012)

8. I.V.Ovsyanikova Informacionnoe modelirovanie adaptivnogo upravlenija jelektrojerozionnoj obrabotkoj // I.V. Ovsyanikova, E.A. Sychev, A.S. 
Tarapanov «Fundamental'nye i prikladnye problemy tehniki i tehnologii» №5, Gosuniversitet - UNPK, Orel, p.103-107 (2013)

9. Stuart J. Russell \& Peter Norvig Artificial Intelligence: A Modern Approach (2nd ed.), Upper Saddle River, New Jersey: Prentice Hall p.460 (2003)

10. Ryshard Tadeusevich, Barbara Borovik, Tomash Gonchazh, Bartosh Lepper Jelementarnoe vvedenie $\mathrm{v}$ tehnologiju nejronnyh setej s primerami programm / Perevod I. D. Rudinskogo. — M.: Gorjachaja linija
- Telekom, 408 p. (2011)

11. Rutkovskij Leshek Metody $i$ tehnologii iskusstvennogo intellekta Per. s pol'sk. I. D. Rudinskogo Izdatel'stvo: Gorjachaja linija Telekom, 520p. (2010) 